\title{
5-(4-Ammonio-2-Oxopyrimidine-1(2H)-yl)-1,3-Oxathiolane-2- Carboxylate (lamivudine acid) Semihydrate: The Six-Fold Symmetry Created by Hydrogen Bond Network
}

\author{
Grzegorz Dutkiewicz • C. S. Chidan Kumar • \\ H. S. Yathirajan · B. Narayana $\cdot$ Maciej Kubicki
}

Received: 11 November 2009/Accepted: 5 August 2010/Published online: 22 August 2010

(C) The Author(s) 2010. This article is published with open access at Springerlink.com

\begin{abstract}
The title compound, $\mathrm{C}_{8} \mathrm{H}_{9} \mathrm{~N}_{3} \mathrm{O}_{4} \mathrm{~S} \times 1 / 2\left(\mathrm{H}_{2} \mathrm{O}\right)$, which is an impurity found in a drug lamivudine, crystallizes in the hexagonal space group $\mathrm{P}_{2}$ with a $=10.208(1) \AA$ and $\mathrm{c}=18.073(2) \AA$. Such a rare packing is constructed by the hierarchical network of hydrogen bonds, which connect the molecules into chains, then into pairs of chains, and neighboring chains, oriented at the angle of $60^{\circ}$, make the final packing mode. The molecule exists in the crystal as the zwitterion, with negative charged carboxylate and positive ammonio groups. The oxathiolane ring is close to an envelope conformation, and both pyrimidine and carboxylate substituent are in the equatorial positions.
\end{abstract}

Keywords Oxathiolane ring - Hydrogen bonds - Crystal packing $\cdot$ Lamivudine

\section{Results and Discussion}

Lamivudine (which is a common name for 4-amino-1-(2R, $5 \mathrm{~S}$ )-[2-(hydroxymethyl)-1,3-oxathiolan-5-yl]pyrimidin-2(1H)one) is a reverse transcriptase inhibitor used in the treatment of HIV infection alone or in combination with other class

G. Dutkiewicz · M. Kubicki $(\square)$

Department of Chemistry, Adam Mickiewicz University, Grunwaldzka 6, 60-780 Poznań, Poland

e-mail: mkubicki@amu.edu.pl

C. S. Chidan Kumar · H. S. Yathirajan

Department of Studies in Chemistry, University of Mysore,

Manasagangotri 570 006, Mysore, India

B. Narayana

Department of Studies in Chemistry, Mangalore University, Mangalagangotri 574 199, India of Anti HIV drugs. It is an antiretroviral agent, which belongs to a class of drugs called "nucleoside reverse transcripts inhibitors" or "NRTIs". The drug is marketed by GlaxoSmithKline with the brand names Zeffix, Heptovir, Epivir, and Epivir-HBV. Lamivudine and its hydrate have been studied [1]. The identification of lamivudine conformers by Raman scattering measurements and quantum chemical calculations is reported [2]. Lamivudine acid-or 5-(4-amino-2-oxopyrimidine-1(2H)-yl)-1,3-oxathiolane-2-carboxylic acid is an impurity which can be present in the drug lamivudine. In view of the importance of lamivudine, the paper reports the synthesis and crystal structure of lamivudine acid, $\mathrm{C}_{8} \mathrm{H}_{9} \mathrm{~N}_{3} \mathrm{O}_{4} \mathrm{~S}$, which turned out to crystallize in a zwitterionic form, and additionally as a hydrate (I, Scheme 1).

Figure 1 shows the perspective view of the molecule, and Table 1 lists the relevant geometrical parameters. In the crystal structure the molecule of lamivudine acid exists as the zwitterion, with carboxylate anionic and ammonio cationic groups on the opposite ends of the molecule. This is proven by the bond lengths pattern: almost equal $\mathrm{C}-\mathrm{O}$ bonds, short C9-N91 bond (cf. Table 1). The bond lengths and angles pattern is similar to that found in the structure of Lamivudine saccharinate [3], which might be regarded as an additional proof for the protonation site in the sixmembered ring.

The conformation of the oxathiolane ring is close to an envelope, with four atoms: S1, C2, O3 and C5 almost coplanar (maximum deviation from the least-squares plane of $0.033(2) \AA$ ) while the fifth atom (C4) is significantly, by $0.608(5) \AA$ out of this plane. Also the asymmetry parameter [4], which describes the deviation from the ideal symmetry (in this case $C_{s}$ ), has relatively low value of $8.8^{\circ}$. Similar conformation was observed in the majority of the structures with not fused oxathiolane rings found in the 


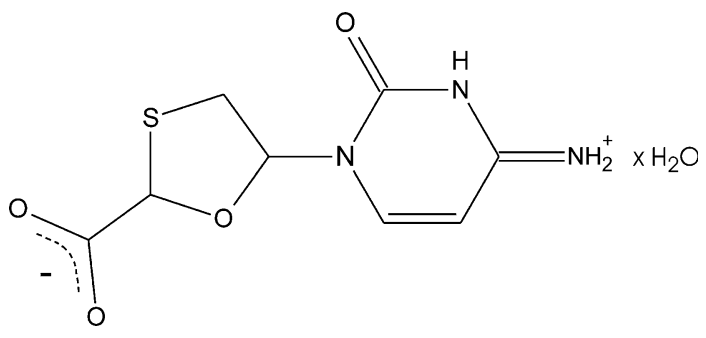

Scheme 1 The lamivudine acid

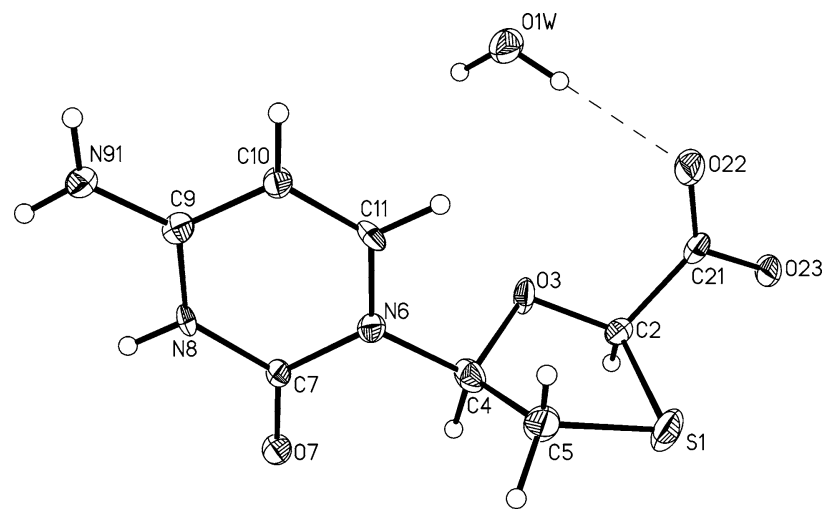

Fig. 1 Anisotropic ellipsoid representation of the compound I together with atom labelling scheme [12]. The ellipsoids are drawn at $50 \%$ probability level, hydrogen atoms are depicted as spheres with arbitrary radii, hydrogen bond is shown as the dashed line

Table 1 Selected geometrical parameters $\left(\AA{ }^{\circ}\right)$

\begin{tabular}{lc}
\hline $\mathrm{S} 1-\mathrm{C} 2$ & $1.855(4)$ \\
$\mathrm{S} 1-\mathrm{C} 5$ & $1.817(4)$ \\
$\mathrm{C} 2-\mathrm{O} 3$ & $1.407(5)$ \\
$\mathrm{O} 3-\mathrm{C} 4$ & $1.428(4)$ \\
$\mathrm{C} 21-\mathrm{O} 22$ & $1.232(4)$ \\
$\mathrm{C} 21-\mathrm{O} 23$ & $1.272(4)$ \\
$\mathrm{N} 6-\mathrm{C} 11$ & $1.364(4)$ \\
$\mathrm{N} 6-\mathrm{C} 7$ & $1.397(5)$ \\
$\mathrm{C} 7-\mathrm{N} 8$ & $1.383(4)$ \\
$\mathrm{N} 8-\mathrm{C} 9$ & $1.359(5)$ \\
$\mathrm{C} 9-\mathrm{N} 91$ & $1.298(5)$ \\
$\mathrm{C} 2-\mathrm{S} 1-\mathrm{C} 5$ & $91.69(18)$ \\
$\mathrm{C} 7-\mathrm{N} 8-\mathrm{C} 9$ & $125.5(3)$ \\
$\mathrm{C} 5-\mathrm{S} 1-\mathrm{C} 2-\mathrm{O} 3$ & $4.6(3)$ \\
$\mathrm{S} 1-\mathrm{C} 2-\mathrm{O} 3-\mathrm{C} 4$ & $-31.6(3)$ \\
$\mathrm{C} 2-\mathrm{O} 3-\mathrm{C} 4-\mathrm{C} 5$ & $50.7(4)$ \\
$\mathrm{O} 3-\mathrm{C} 4-\mathrm{C} 5-\mathrm{S} 1$ & $-43.7(3)$ \\
$\mathrm{C} 4-\mathrm{C} 5-\mathrm{S} 1-\mathrm{C} 2$ & $21.2(3)$ \\
\hline
\end{tabular}

Cambridge Structural Database [5], however different atoms occupy the out-of-plane position. The pyrimidine substituent (which is approximately planar, within
$0.010(2) \AA$ ) occupies the equatorial position with respect to the oxathiolane ring $(\mathrm{C} 2-\mathrm{O} 3-\mathrm{C} 4-\mathrm{N} 6$ torsion angle is 172.9 $\left.(3)^{\circ}, \mathrm{S} 1-\mathrm{C} 5-\mathrm{C} 4-\mathrm{N} 6-160.8(3)^{\circ}\right)$, the position of carboxylate group is also close to the equatorial one (C4-O3-C2$\left.\mathrm{C} 21-149.6(3)^{\circ}, \mathrm{C} 5-\mathrm{S} 1-\mathrm{C} 2-\mathrm{C} 21-125.3(3)^{\circ}\right)$.

Compound 1 crystallizes in a rather uncommon space group $\mathrm{P}_{2}$-in the CSD there are only 61 structures in either $\mathrm{P}_{2}$ or $\mathrm{P}_{4}$ space groups, of which 26 are of organic compounds. The crystal packing is determined mainly by an extensive network of hydrogen bonds (Table 2), both strong $(\mathrm{N}-\mathrm{H} \cdots \mathrm{O}$ (carboxylate), $\mathrm{O}$ (water) $-\mathrm{H} \cdots \mathrm{O}$ (carboxylate) and weak $(\mathrm{C}-\mathrm{H} \cdots \mathrm{O}$ (water, carbonyl)). The organization of the three-dimensional network may be analyzed as the stepby-step construction of the six-fold screw symmetry. At the first level, molecules are connected by means of two different hydrogen bonds: $\mathrm{N} 8-\mathrm{H} 8 \cdots \mathrm{O} 23(x, y-1, z)$ and $\mathrm{N} 91-$ $\mathrm{H} 91 \mathrm{~A} \cdots \mathrm{O} 22(x, y-1, z)$ into the infinite chains expanding along y direction (Fig. 2a). Using the graph-set notation [6,7] one could find, at this level, two parallel chains $C(9)$ and $C(11)$ along $y$, which give rise to the second-order $\mathrm{R}_{2}^{2}(8)$ ring. The neighboring chains are connected by hydrogen bonds with water molecules (which lie on the twofold axes) into the pairs of antiparallel chains; the "linking" graph symbol is $\mathrm{R}_{6}^{4}(30)$, cf. Fig. 2b.

Then, at the next level, these double strands are linked by means of N91-H91B $\cdots \mathrm{O} 23(y,-x+y, z-1 / 3)$ hydrogen bonds with the subsequent strands, which are oriented at the angle of $60^{\circ}$ to the former one (Fig. 2c). At this level relatively short and directional $\mathrm{C} 5-\mathrm{H} 5 \cdots \mathrm{O} 1 \mathrm{~W}^{\mathrm{iii}}$ hydrogen bonds also play their part, by linking the neighbouring chains. Altogether, all these steps lead to the hexagonal symmetry as seen in the packing diagram (Fig. 3).

\section{Experimental}

Preparation

L-menthyl-5-cytosin-1,3-oxathiolane-2-carboxylate(2.0 g, $5.2 \mathrm{mmol})$ was added to a solution of $\mathrm{KOH}(0.3 \mathrm{~g}$, $6.0 \mathrm{mmol}$ ) in $20 \mathrm{ml}$ of methanol (Scheme 2). The mixture was stirred for $4 \mathrm{~h}$. Methanol was distilled out and the residue was diluted with water. Aqueous layer was extracted with ethyl acetate. The $\mathrm{pH}$ of aqueous layer was adjusted to four using acetic acid. The solid was collected by filtration and further recrystallized from water (m.p.: 311-313 K).

\section{Crystallography}

Colourless block-like crystal $(0.2,0.1,0.1 \mathrm{~mm})$ was used for data collection. Diffraction data were collected at 100(1)K 
Fig. 2 The construction of the packing motifs. a the hydrogen bonded chain along $\mathbf{y} ; \mathbf{b}$ the pair of antiparallel chains; $\mathbf{c}$ the set of strands giving the six-fold symmetry

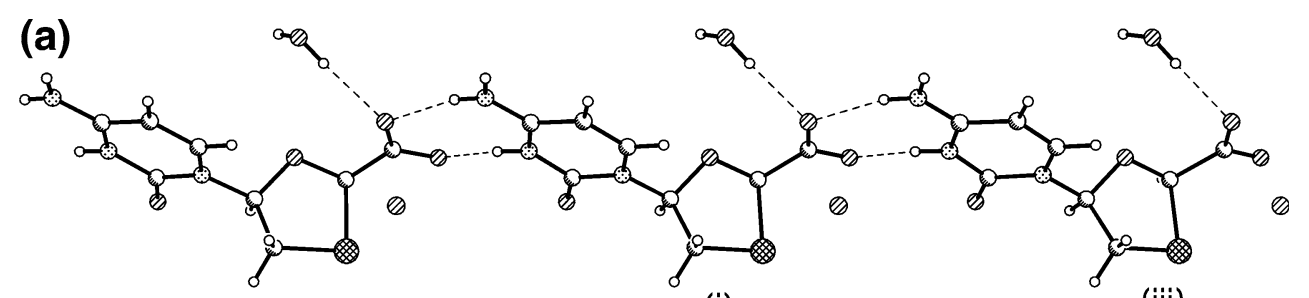

(ii)

(i)

(iii)

(b)

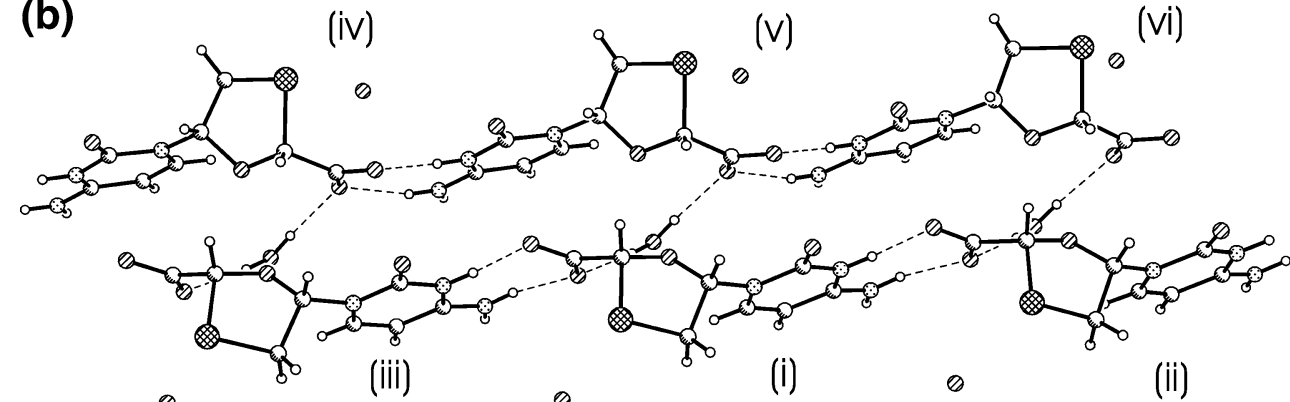

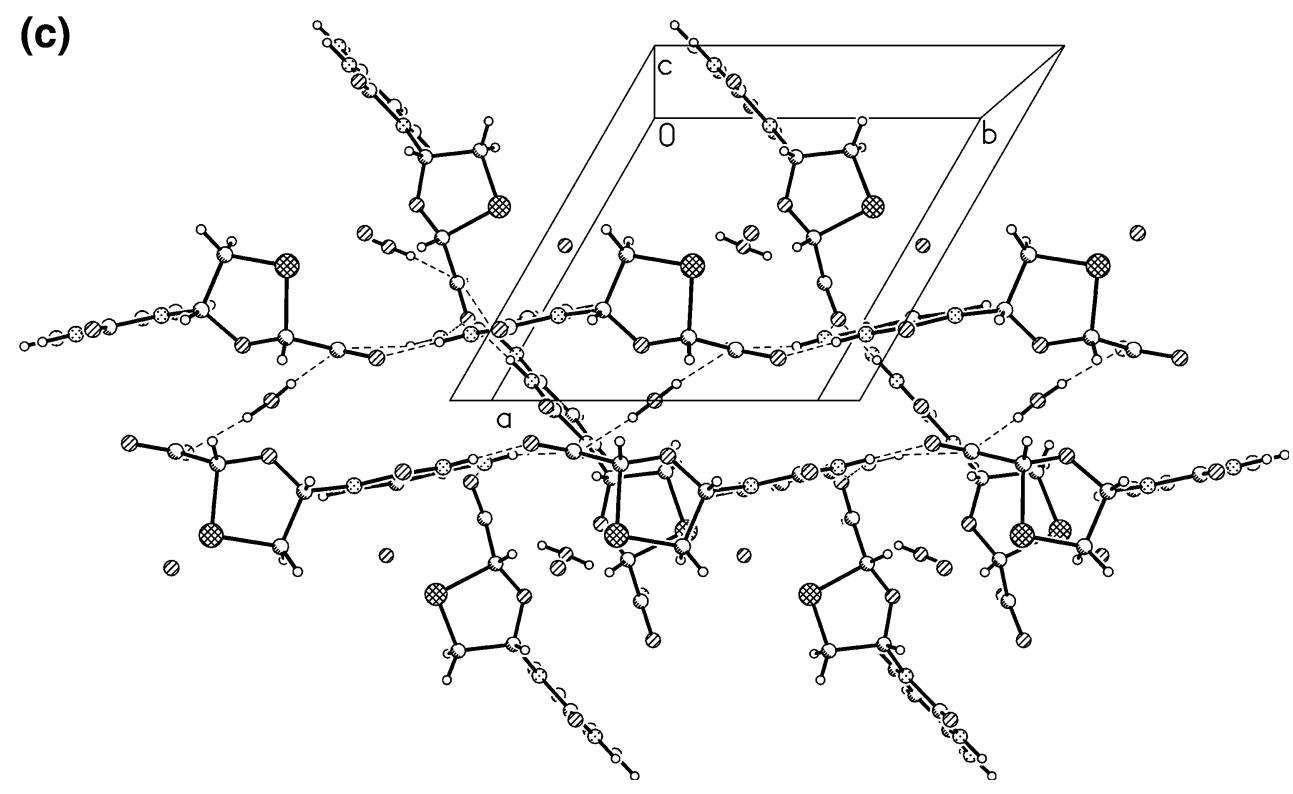

Table 2 Hydrogen-bond geometry $\left(\AA{ }^{\circ}\right.$ )

\begin{tabular}{lllll}
\hline $\mathrm{D}-\mathrm{H} \cdots \mathrm{A}$ & $\mathrm{D}-\mathrm{H}$ & $\mathrm{H} \cdots \mathrm{A}$ & $\mathrm{D} \cdots \mathrm{A}$ & $\mathrm{D}-\mathrm{H} \cdots \mathrm{A}$ \\
\hline $\mathrm{N} 8-\mathrm{H} 8 \cdots \mathrm{O} 23^{\mathrm{i}}$ & 0.88 & 1.81 & $2.681(4)$ & 173 \\
$\mathrm{~N}^{\mathrm{N}} \mathrm{H}-\mathrm{H} 91 \mathrm{~A} \cdots \mathrm{O} 22^{\mathrm{i}}$ & 0.88 & 2.01 & $2.873(4)$ & 168 \\
$\mathrm{~N}^{\mathrm{N}} \mathrm{-H} 91 \mathrm{~B} \cdots \mathrm{O} 23^{\mathrm{ii}}$ & 0.88 & 2.01 & $2.870(4)$ & 166 \\
$\mathrm{C} 5-\mathrm{H} 5 \mathrm{~A} \cdots \mathrm{O} 1 \mathrm{~W}^{\mathrm{iii}}$ & 0.99 & 2.34 & $3.202(5)$ & 145 \\
$\mathrm{O} 1 \mathrm{~W}-\mathrm{H} 1 \mathrm{~W} 1 \cdots \mathrm{O} 22$ & 0.85 & 2.06 & $2.885(3)$ & 173 \\
\hline
\end{tabular}

Symmetry codes: (i) $x, y-1, z$; (ii) $y,-x+y, z-1 / 3$; (iii) $-x+y+1,-x+1, z+1 / 3$

by the $\omega$-scan technique up to $2 \theta=60^{\circ}$, on an Xcalibur diffractometer [8] with graphite-monochromatized $\mathrm{MoK}_{\alpha}$ radiation $(\lambda=0.71073 \AA)$. The temperature was controlled

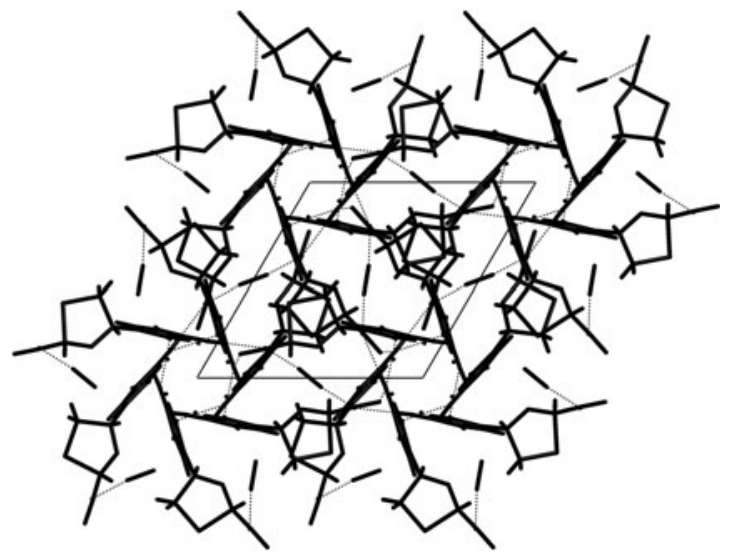

Fig. 3 The packing diagram as seen along $c$-direction [13] 
Scheme 2 Synthesis of the lamivudine acid<smiles>CC1CCC(C(C)C)C(OC(=O)C2OC(n3ccc(N)nc3=O)CS2)C1</smiles>

by an Oxford Instruments Cryosystems cooling device. The data were corrected for Lorentz-polarization and absorption effects [8]. Accurate unit-cell parameters were determined by a least-squares fit of 2307 reflections of highest intensity, chosen from the whole experiment. The structures were solved with SIR92 [9] and refined with the full-matrix leastsquares procedure on $\mathrm{F}^{2}$ by SHELXL97 [10]. Scattering factors incorporated in SHELXL97 were used. The function $\sum \mathrm{w}\left(\left|\mathrm{F}_{\mathrm{o}}\right|^{2}-\left|\mathrm{F}_{\mathrm{c}}\right|^{2}\right)^{2}$ was minimized, with $\mathrm{w}^{-1}=\left[\sigma^{2}\left(\mathrm{~F}_{\mathrm{o}}\right)^{2}+\right.$ $\left.0.0951 \cdot \mathrm{P}^{2}+0.2763 \cdot \mathrm{P}\right]\left(\mathrm{P}=\left[\operatorname{Max}\left(\mathrm{F}_{\mathrm{o}}^{2}, 0\right)+2 \mathrm{~F}_{\mathrm{c}}^{2}\right] / 3\right)$. All non-hydrogen atoms were refined anisotropically, hydrogen atoms were put in the idealized positions (only that from water molecule was found in the difference Fourier map), and refined as riding model. Their isotropic thermal

Table 3 Crystal data, data collection and structure refinement

\begin{tabular}{|c|c|}
\hline Formula & $\mathrm{C}_{8} \mathrm{H}_{9} \mathrm{~N}_{3} \mathrm{O}_{4} \mathrm{~S} \cdot 1 / 2 \mathrm{H}_{2} \mathrm{O}$ \\
\hline Formula weight & 167.67 \\
\hline Crystal system & Hexagonal \\
\hline Space group & $\mathrm{P}_{2}$ \\
\hline $\mathrm{a}(\AA)$ & $10.208(1)$ \\
\hline c $(\AA)$ & $18.073(2)$ \\
\hline$V\left(\AA^{3}\right)$ & $1631.0(3)$ \\
\hline $\mathrm{Z}$ & 6 \\
\hline$D_{x}\left(\mathrm{~g} \mathrm{~cm}^{-3}\right)$ & 1.56 \\
\hline$F(000)$ & 798 \\
\hline$\mu\left(\mathrm{mm}^{-1}\right)$ & 0.31 \\
\hline$\Theta$ range $\left({ }^{\circ}\right)$ & $3.22-24.99$ \\
\hline hkl range & $\begin{array}{l}-10 \leq \mathrm{h} \leq 12 \\
-12 \leq \mathrm{k} \leq 7 \\
-21 \leq 1 \leq 21\end{array}$ \\
\hline \multicolumn{2}{|l|}{ Reflections: } \\
\hline Collected & 3196 \\
\hline Unique ( $\left.\mathrm{R}_{\text {int }}\right)$ & $1715(0.046)$ \\
\hline With $\mathrm{I}>2 \sigma(\mathrm{I})$ & 1531 \\
\hline Number of parameters & 155 \\
\hline $\mathrm{R}(\mathrm{F})[\mathrm{I}>2 \sigma(\mathrm{I})]$ & 0.056 \\
\hline$w R\left(\mathrm{~F}^{2}\right)[\mathrm{I}>2 \sigma(\mathrm{I})]$ & 0.143 \\
\hline $\mathrm{R}(\mathrm{F})$ [all data] & 0.062 \\
\hline$w R\left(F^{2}\right)$ [all data] & 0.146 \\
\hline Goodness of fit & 1.107 \\
\hline $\operatorname{Max} / \min \Delta \rho\left(\mathrm{e} \AA^{-3}\right)$ & $0.79 /-0.43$ \\
\hline
\end{tabular}

parameters were set at 1.2 times $\mathrm{U}_{\mathrm{eq}}$ 's of appropriate carrier atoms. There are cavities on the two-fold axis which appeared to be filled by highly disordered water molecule; relatively satisfactory results were obtained with half occupancy, but the displacement parameters were very large. Therefore, we decided that the disorder is so severe that in fact it is smeared-out electron density. As an alternative strategy, the SQUEEZE function of PLATON [11] was used to eliminate the contribution of the electron density in the solvent region from the intensity data. The use of this strategy and the subsequent solvent-free model produced better refinement parameters and more precise geometric parameters, than the model with the disordered water molecule. Relevant crystal data are listed in Table 3, together with refinement details.

CCDC-753804 contains supplementary crystallographic data for this paper. These data can be obtained free of charge via www.ccdc.cam.ac.uk/data_request/cif, by e-mailing data_request@ccdc.cam.ac.uk, or by contacting The Cambridge Crystallographic Data Centre, 12 Union Road, Cambridge CB2 1EZ, UK.

Acknowledgments CSC thanks University of Mysore for research facilities.

Open Access This article is distributed under the terms of the Creative Commons Attribution Noncommercial License which permits any noncommercial use, distribution, and reproduction in any medium, provided the original author(s) and source are credited.

\section{References}

1. Harris RK, Yeung RR, Lamont RB, Lancaster RW, Lynn SM, Staniforth SE (1997) J Chem Soc., Perkin Trans 2:2653

2. Pereira BG, Vianna-Soares CD, Righi A, Pinheiro MVB, Flores MZS, Bezerra EM, Freire VN, Lemos V, Caetano EWS, Cavada BS (2007) J Pharm Biomed Anal 43:1885

3. Banerjee R, Bhatt PM, Ravindra MV, Desiraju GR (2005) Cryst Growth Des 5:2299

4. Duax WL, Norton DA (1975) Atlas of steroid structures. Plenum, New York, pp 16-22

5. Allen FH (2002) Acta Cryst B58:380

6. Etter MC, MacDonald JC, Bernstein J (1990) Acta Cryst B46:256

7. Bernstein J, Davis RE, Shimoni L, Chang N-L (1995) Angew Chem Int Ed Engl 34:1555

8. Oxford Diffraction (2009) CrysAlis PRO (Version 1.171.33.36d). Oxford Diffraction Ltd, Yarnton, Oxfordshire 
9. Altomare A, Cascarano G, Giacovazzo C, Gualardi A (1993) J Appl Cryst 26:343

10. Sheldrick GM (2008) Acta Cryst A64:112

11. van der Sluis P, Spek AL (1990) Acta Cryst A46:194

12. Siemens (1989) Stereochemical workstation operation manual. Release 3.4. Siemens Analytical X-ray Instruments Inc, Madison, Wisconsin, USA
13. Macrae CF, Bruno IJ, Chisholm JA, Edgington PR, McCabe P, Pidcock E, Rodriguez-Monge L, Taylor R, van de Streek J, Wood PA (2008) J Appl Cryst 41:466 